\title{
Tocilizumab Patterns of Use, Effectiveness, and Safety in Patients with Rheumatoid Arthritis: Final Results from a Set of Multi-National Non-Interventional Studies
}

Boulos Haraoui · Gustavo Casado · László Czirják • Andrew Taylor •

Lingli Dong $\cdot$ Peter Button $\cdot$ Yves Luder $\cdot$ Roberto Caporali

Received: January 16, 2019 / Published online: March 11, 2019

(C) The Author(s) 2019

\section{ABSTRACT}

Introduction: The objective of this study was to observe the patterns of usage, efficacy, and safety of tocilizumab (TCZ) in clinical practice in patients with rheumatoid arthritis.

Methods: Data on the real-world usage, efficacy, and safety of TCZ were collected from patients during routine follow-up visits conducted over a 6-month period. Patients were

Enhanced Digital Features To view enhanced digital features for this article go to: https://doi.org/10.6084/ m9.figshare.7775939.

Electronic supplementary material The online version of this article (https://doi.org/10.1007/s40744$019-0150-x)$ contains supplementary material, which is available to authorized users.

B. Haraoui $(\bowtie)$

Institut de Rhumatologie de Montréal, Montreal, Canada

e-mail: paulharaoui@videotron.ca

G. Casado

Department of Rheumatology, Hospital Militar

Central, Buenos Aires, Argentina

L. Czirják

Rheumatology and Immunology Clinic, Medical

Center, University of Pécs, Pécs, Hungary

A. Taylor

Medicine and Pharmacology RPH Unit, Royal Perth

Hospital, University of Western Australia, Perth,

Australia grouped by previous exposure to biologic therapies (biologic exposed vs. biologic naive).

Results: Of 1912 patients enrolled from 16 countries, 639 (33.4\%) received TCZ monotherapy and $1273(66.6 \%)$ received TCZ combination therapy. At baseline, 1073 patients (56.1\%) were biologic naive and 839 (43.9\%) were biologic exposed. At 6 months, 1504 patients $(78.7 \%)$ continued to receive TCZ treatment, with no descriptive differences in retention rates between biologic-exposed and biologic-naive patients and between patients receiving TCZ monotherapy or combination therapy. Dose and use of methotrexate and prednisone were reduced at 6 months. Efficacy at 6 months, including patient-reported outcomes, was demonstrated in both biologicnaive and biologic-exposed groups. Adverse

\footnotetext{
L. Dong

Department of Rheumatology and Immunology, Tongji Hospital, Tongji Medical College, Huazhong University of Science and Technology, Wuhan, Hubei, China

P. Button

OzBiostat Pty Ltd, Manly, Australia

Y. Luder

F. Hoffmann-La Roche, Ltd, Basel, Switzerland

R. Caporali

Department of Rheumatology, University of Pavia, IRCCS S. Matteo Foundation, Pavia, Italy
} 
events (AEs) occurred in 817 patients [42.7\%; incidence rate: 179 events per 100 patient-years (PY)], and serious AEs (SAEs) occurred in 118 patients (6.2\%; 17 events per $100 \mathrm{PY})$, with comparable rates of AEs and SAEs between subgroups.

Conclusion: In routine clinical practice, TCZ discontinuation rates were low and unaffected by prior use of biologics. Effectiveness was similar between groups, and no new safety signals were identified.

Funding: F. Hoffmann-La Roche.

Keywords: ACT-UP; Biologic factors; Rheumatoid arthritis; Tocilizumab

\section{INTRODUCTION}

Rheumatoid arthritis (RA) is a chronic and debilitating autoimmune disease characterized by inflammation of the joints [1]. Treatment of RA seeks to alleviate disease signs and symptoms, including pain and inflammation, to reduce joint damage, to preserve function and quality of life (QOL), and to prevent premature mortality associated with this disorder [2]. Firstline treatments for RA include conventional synthetic disease-modifying antirheumatic drugs (csDMARDs) such as methotrexate (MTX) [3]; however, many patients have an inadequate response to MTX and other csDMARDs. In these patients, the addition of a biologic therapy is recommended. Although tumor necrosis factor alpha inhibitors (TNFis) are often the first choice for a biologic therapy, 30-40\% of patients may not respond to TNFi treatment [4-6]. In these patients, a biologic with a different mechanism of action may be more effective.

The biologic DMARD tocilizumab (TCZ) is a humanized monoclonal antibody targeting the interleukin-6 receptor. TCZ is approved worldwide for the treatment of RA in patients who have had an inadequate response to one or more csDMARDs and, in the European Union, in patients who are MTX naive $[7,8]$. TCZ has demonstrated efficacy in patients with an inadequate response to csDMARDs or TNFis [9-12] and in patients who are MTX naive
$[13,14]$, and it has been shown to be effective when administered as monotherapy or in combination with MTX [15-18].

We previously reported that in routine clinical practice, patients had a high rate of persistence with both TCZ monotherapy and TCZ plus csDMARDs [19]. This finding was coupled with a high rate of efficacy with both treatment protocols. Our current study describes realworld information on the patterns of usage of TCZ in patients with RA with regard to drug persistence and adherence to the licensed label recommendations for TCZ. This study expands on our previous report [19], with a complete data set containing information collected from 576 additional patients. Furthermore, this analysis describes patient-reported outcomes (PROs) and differences in outcomes among patients who were biologic naive vs. biologic experienced at baseline.

\section{METHODS}

\section{Study Design}

Global analysis was performed on data pooled from independent local studies contributing to the ACT-UP umbrella project, which were conducted in 16 countries and shared similar designs, patient selection criteria, and core data. Patients with RA initiating intravenous TCZ were followed up over a 6-month observation period. The dose of TCZ and duration of treatment were determined according to the investigator's judgment and in accordance with the label and local regulations. The eligibility criteria for participation have been described [19]. Briefly, participants were $\geq 18$ years of age, had a diagnosis of moderate to severe RA according to the revised (1987) American College of Rheumatology criteria [20], and had received TCZ for $<8$ weeks prior to the enrollment visit. All procedures performed in studies involving human participants were in accordance with the 1964 Helsinki Declaration and its later amendments or comparable ethical standards. Informed consent was obtained from all individual participants included in the study. As ACT-UP was an umbrella study, the study 
protocols, amendments, and informed consent documentation were approved by the respective local institutional review boards or independent ethics committees of the investigational centers.

\section{Assessments}

Data were collected over a 6-month period on TCZ efficacy, safety, and patterns of use. Assessment of efficacy was evaluated using Disease Activity Score 28 (DAS28) scores. Additional efficacy end points of interest were QOL and disability measures, including Patient Global Assessment of Disease Activity, Health Assessment Questionnaire-Disability Index (HAQ-DI), and visual analog scales to evaluate the severity of fatigue, pain, and morning stiffness. Adverse events (AEs) and serious AEs (SAEs) were recorded to evaluate safety and were collected and reported by system organ class. When available, laboratory results were evaluated for clinically significant abnormalities.

\section{Statistical Analysis}

Data from all 16 countries were pooled for analysis. Patients were stratified into groups based on treatment (TCZ monotherapy vs. TCZ combination therapy) and on biologic exposure at baseline (naive vs. exposed). Baseline values could be evaluated prior to the first TCZ treatment. Analyses were primarily performed using descriptive statistical methods. For KaplanMeier estimates, 95\% CIs were computed.

\section{RESULTS}

\section{Patient Disposition and Baseline Characteristics}

A total of 1912 patients were enrolled in 16 countries (Table S1), of whom 1073 (56.1\%) were biologic naive and 839 (43.9\%) were biologic exposed (Fig. 1) Overall, 1504 patients $(78.7 \%)$ completed the study at month 6 . The mean (SD) duration of TCZ treatment was 192.3 (83.0) days. More patients received combination therapy (1273 patients; 66.6\%) than TCZ monotherapy (639 patients; 33.4\%). A total of

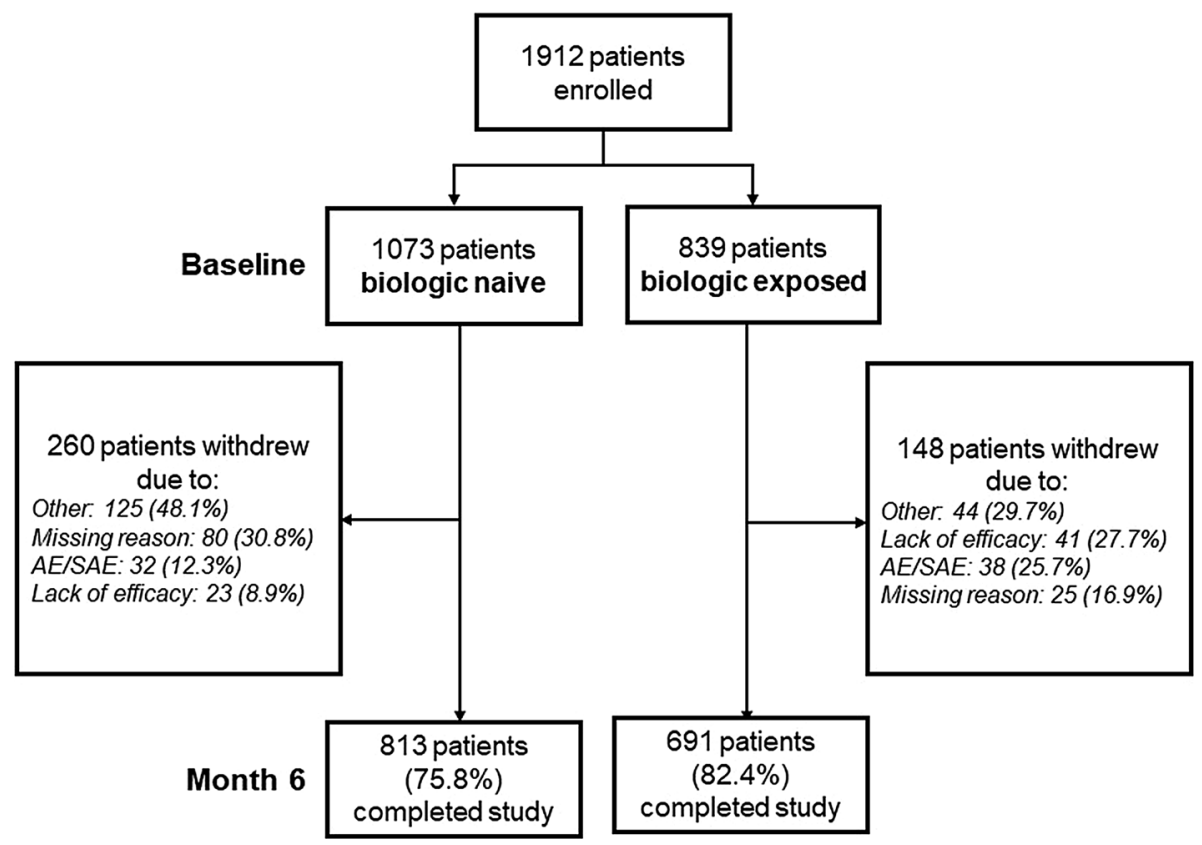

Fig. 1 Patient disposition. $A E$ adverse event, $S A E$ serious adverse event 
895 patients (46.8\%) received concomitant corticosteroids.

Baseline demographics and disease characteristics were similar between patients who were biologic naive and those who were biologic exposed at baseline and between those receiving TCZ monotherapy and those receiving combination therapy (Table 1).

\section{TCZ Retention}

Overall, 359 patients (18.8\%) discontinued TCZ during the study. Kaplan-Meier curves for persistence are shown in Fig. 2. A total of 199 biologic-naive patients (18.6\%) and 160 biologicexposed patients (19.1\%) discontinued TCZ; Kaplan-Meier estimates for the proportions of patients still receiving TCZ at 24 weeks were 81.3\% (95\% CI, 78.7-83.7\%) for biologic-naive patients and $82.3 \%$ (95\% CI, 79.4-84.7\%) for biologic-exposed patients (Fig. 2a). A total of 147 patients $(23.0 \%)$ receiving TCZ monotherapy and 212 patients $(16.7 \%)$ receiving combination therapy discontinued TCZ; Kaplan-Meier estimates for the proportions of patients still receiving TCZ at 24 weeks were $78.3 \%$ (95\% CI, $74.8 \%-81.4 \%$ ) for TCZ monotherapy and $83.5 \%$ (95\% CI, 81.2\%-85.5\%) for TCZ combination therapy (Fig. 2b). Of 407 patients enrolled in China (the country with the largest proportion of enrolled patients; Table S1), 296 patients completed the study and 111 discontinued the study prematurely. The primary reason for premature discontinuation of TCZ in China was treatment costs.

\section{Concomitant Treatments}

A total of 1353 patients $(70.8 \%)$ received $\geq 1$ DMARD during the study period (Table 2). The most common DMARDs were MTX (56.0\%), leflunomide (22.9\%), hydroxychloroquine $(20.8 \%)$, and sulfasalazine $(10.9 \%)$. Of patients receiving TCZ, 914/1912 (47.8\%) received concomitant MTX at baseline, and 647/1504 $(43.0 \%)$ received concomitant MTX at month 6. Of the patients receiving MTX, mean (SD) dose of MTX was similar at initiation [14.4 (5.1) mg per week] and month 6 [14.5 (5.1) mg per week].
Of the 99 patients with a change in MTX dose during the study period, the mean (SD) dose change was -2.9 (5.5) $\mathrm{mg}$ per week. Overall, 30 patients had increases in MTX dose and 75 had decreases. The number of patients receiving concomitant corticosteroids was 796/1912 $(41.6 \%)$ at baseline and 615/1504 (40.9\%) at month 6. Of these patients, mean (SD) prednisone-equivalent dose was 8.5 (5.4) $\mathrm{mg}$ per day at baseline and 7.7 (4.9) $\mathrm{mg}$ per day at month 6 . Of the 217 patients with a change in corticosteroid dose during the study period, the mean (SD) dose change was - 2.2 (9.0) $\mathrm{mg}$ per day.

\section{Efficacy}

Overall, mean (SD) DAS28 scores decreased from baseline to month 6 [5.82 (1.24) to 2.65 (1.37)], with $69.8 \%$ of patients achieving DAS28 remission (DAS28 $<2.6,52.8 \%$ ) or low disease activity (LDA; $2.6 \leq$ DAS2 $8 \leq 3.2,17.0 \%$ ) at month 6. The proportion of patients who achieved DAS28 remission or LDA was similar between biologic-naive $(72.8 \%$; remission: 55.6\%; LDA: 17.1\%) and biologic-exposed (66.3\%; remission: 49.4\%; LDA: 16.9\%) patients.

Decreases in mean (SD) scores were reported for all patient- and physician-reported outcomes, which included patient assessment of RA pain [- $32.4(28.8) \mathrm{mm}$ ], patient assessment of disease activity [- $32.8(28.6) \mathrm{mm}]$, patient assessment of morning stiffness [- 31.8 (30.1) $\mathrm{mm}]$, physician assessment of disease activity [- $36.0(26.0) \mathrm{mm}]$, and HAQ-DI score [- 0.6 (0.7)]; changes were similar between biologicnaive and biologic-exposed patients (Fig. 3). The number of patients with morning stiffness decreased from 1368/1482 (92.3\%) at baseline to $591 / 981(60.2 \%)$ at month 6 . At baseline, $50.0 \%$ of patients reported $>60$ min of morning stiffness daily, $30.4 \%$ had 30 to $60 \mathrm{~min}$, and $19.6 \%$ had $<30$ min. At 6 months, $21.1 \%$ had $>60$ min of morning stiffness daily, $26.4 \%$ had 30 to $60 \mathrm{~min}$, and $52.3 \%$ had $<30 \mathrm{~min}$ (Fig. 4). Patients who were biologic naive showed numerically better improvement in all PROs than patients who were biologic exposed. A meaningful reduction $(\geq 0.22)$ in HAQ-DI 
Table 1 Baseline demographics and disease characteristics

\begin{tabular}{|c|c|c|c|c|c|}
\hline \multirow[t]{2}{*}{ Parameter, mean $(S D)^{a}$} & \multicolumn{2}{|c|}{ Baseline biologic experience } & \multicolumn{2}{|c|}{ Baseline TCZ treatment } & \multirow{2}{*}{$\begin{array}{l}\text { All patients } \\
n=1912\end{array}$} \\
\hline & $\begin{array}{l}\text { Biologic } \\
\text { naïve } \\
n=1073\end{array}$ & $\begin{array}{l}\text { Biologic } \\
\text { exposed } \\
n=839\end{array}$ & $\begin{array}{l}\text { TCZ } \\
\text { monotherapy } \\
n=639\end{array}$ & $\begin{array}{l}\text { TCZ } \\
\text { combination therapy } \\
n=1273\end{array}$ & \\
\hline Age, years & $51.7(13.4)$ & $54.9(13.3)$ & $54.5(13.3)$ & $52.4(13.4)$ & $53.1(13.4)$ \\
\hline Female, $n(\%)$ & $881(82.2)$ & $698(83.2)$ & $512(80.3)$ & $1067(83.8)$ & $1579(82.6)$ \\
\hline Male, $n(\%)$ & $191(17.8)$ & $141(16.8)$ & $126(19.7)$ & $206(16.2)$ & $332(17.4)$ \\
\hline Duration of RA, years & $6.9(7.4)$ & $11.4(9.9)$ & $9.7(10.0)$ & $8.5(8.3)$ & $8.9(8.9)$ \\
\hline $\begin{array}{l}\text { Duration of TCZ treatment, } \\
\text { days }\end{array}$ & $176.8(74.9)$ & $212.1(88.5)$ & $188.5(83.9)$ & $194.2(82.5)$ & $192.3(83.0)$ \\
\hline $\begin{array}{l}\text { Patient assessment of RA pain } \\
\text { on VAS, mm }\end{array}$ & $62.3(23.0)$ & $64.2(22.4)$ & $63.6(22.6)$ & $63.0(22.9)$ & $63.2(22.8)$ \\
\hline $\begin{array}{l}\text { Patient assessment of disease } \\
\text { activity on VAS, } \mathrm{mm}\end{array}$ & $63.4(22.7)$ & $66.1(21.7)$ & $65.6(21.0)$ & $64.2(22.8)$ & $64.6(22.2)$ \\
\hline $\begin{array}{l}\text { Patient assessment of fatigue } \\
\text { on VAS, } \mathrm{mm}\end{array}$ & $57.3(26.2)$ & $63.0(24.0)$ & $59.2(25.2)$ & $59.7(25.7)$ & $59.6(25.5)$ \\
\hline $\begin{array}{l}\text { Patient assessment of morning } \\
\text { stiffness on VAS, } \mathrm{mm}\end{array}$ & $54.0(27.8)$ & $58.3(26.1)$ & $56.4(26.0)$ & $55.5(27.7)$ & $55.8(27.2)$ \\
\hline $\begin{array}{l}\text { Patients with morning } \\
\text { stiffness, } n(\%)\end{array}$ & $763(91.9)$ & $605(92.8)$ & $424(92.0)$ & $944(92.5)$ & $1368(92.3)$ \\
\hline $\begin{array}{l}\text { Physician assessment of } \\
\text { disease activity on VAS, } \mathrm{mm}\end{array}$ & $58.9(22.1)$ & $60.4(21.4)$ & $58.2(22.6)$ & $60.2(21.4)$ & $59.6(21.8)$ \\
\hline HAQ-DI ${ }^{\mathrm{b}}$ & $1.6(0.8)$ & $1.6(0.7)$ & $1.6(0.8)$ & $1.6(0.8)$ & $1.6(0.8)$ \\
\hline DAS28 $8^{\mathrm{c}}$ & $6.0(1.3)$ & $5.7(1.2)$ & $5.7(1.3)$ & $5.9(1.2)$ & $5.8(1.2)$ \\
\hline CDAI & $33.6(14.7)$ & $32.2(13.4)$ & $31.8(14.1)$ & $33.7(14.3)$ & $33.1(14.2)$ \\
\hline SDAI & $36.9(16.2)$ & $34.6(14.2)$ & $34.3(15.4)$ & $36.6(15.4)$ & $35.9(15.4)$ \\
\hline TJC28 & $12.5(7.7)$ & $11.4(7.3)$ & $11.0(7.4)$ & $12.5(7.6)$ & $12.0(7.5)$ \\
\hline SJC28 & $8.8(6.6)$ & $7.3(5.8)$ & $7.6(6.1)$ & $8.4(6.3)$ & $8.1(6.3)$ \\
\hline $\mathrm{ESR}, \mathrm{mm} / \mathrm{h}$ & $45.9(31.9)$ & $36.3(26.3)$ & $41.2(30.6)$ & $42.1(29.7)$ & $41.8(30.0)$ \\
\hline CRP, mg/l & $30.7(47.3)$ & $22.1(29.3)$ & $24.8(35.6)$ & $27.9(42.8)$ & $26.9(40.6)$ \\
\hline
\end{tabular}

$C D A I$ clinical disease activity index, CRP C-reactive protein, DAS28 Disease Activity Score using 28 joints, ESR erythrocyte sedimentation rate, $H A Q-D I$ Health Assessment Questionnaire-Disability Index, SDAI simplified disease activity index, SJC28 swollen joint count at 28 joints, TCZ tocilizumab, TJC28 tender joint count at 28 joints, $V A S$ visual analog scale

a Except where otherwise indicated

b HAQ-DI data from Belgian patients were excluded because of use of an alternative scoring system

c DAS28-ESR or, if missing, DAS28-CRP 
a

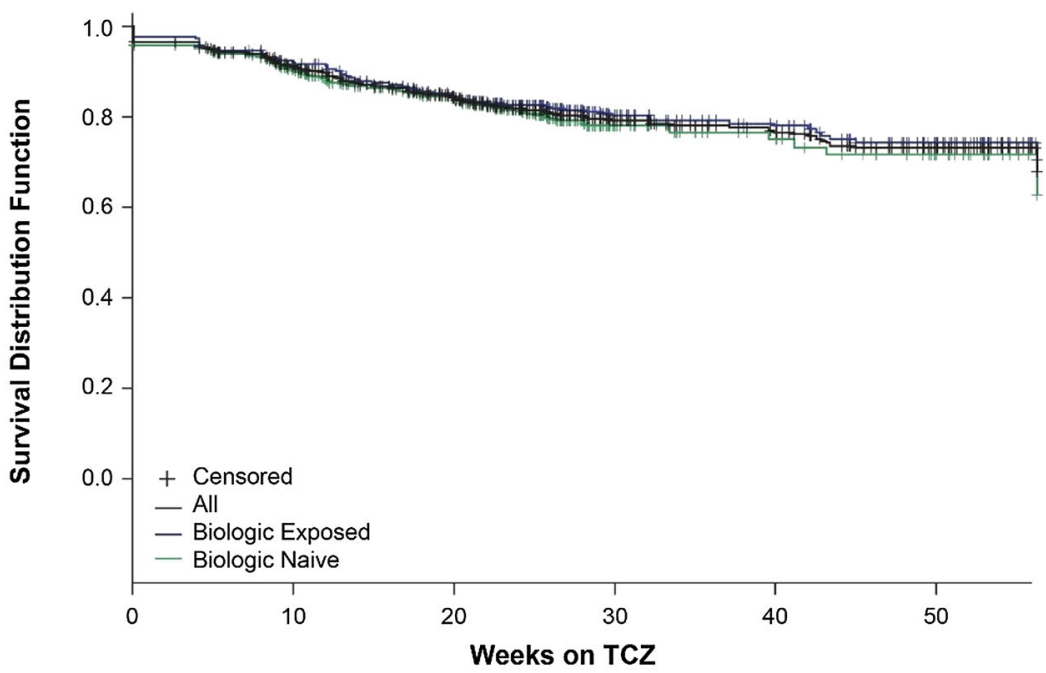

\begin{tabular}{|c|c|c|c|c|c|c|}
\hline \multicolumn{7}{|l|}{ Number of patients at risk } \\
\hline All & 1912 & 1666 & 1422 & 256 & 169 & 108 \\
\hline Biologic Exposed & 839 & 763 & 670 & 170 & 122 & 79 \\
\hline Biologic Naive & 1073 & 903 & 752 & 86 & 47 & 29 \\
\hline
\end{tabular}

b

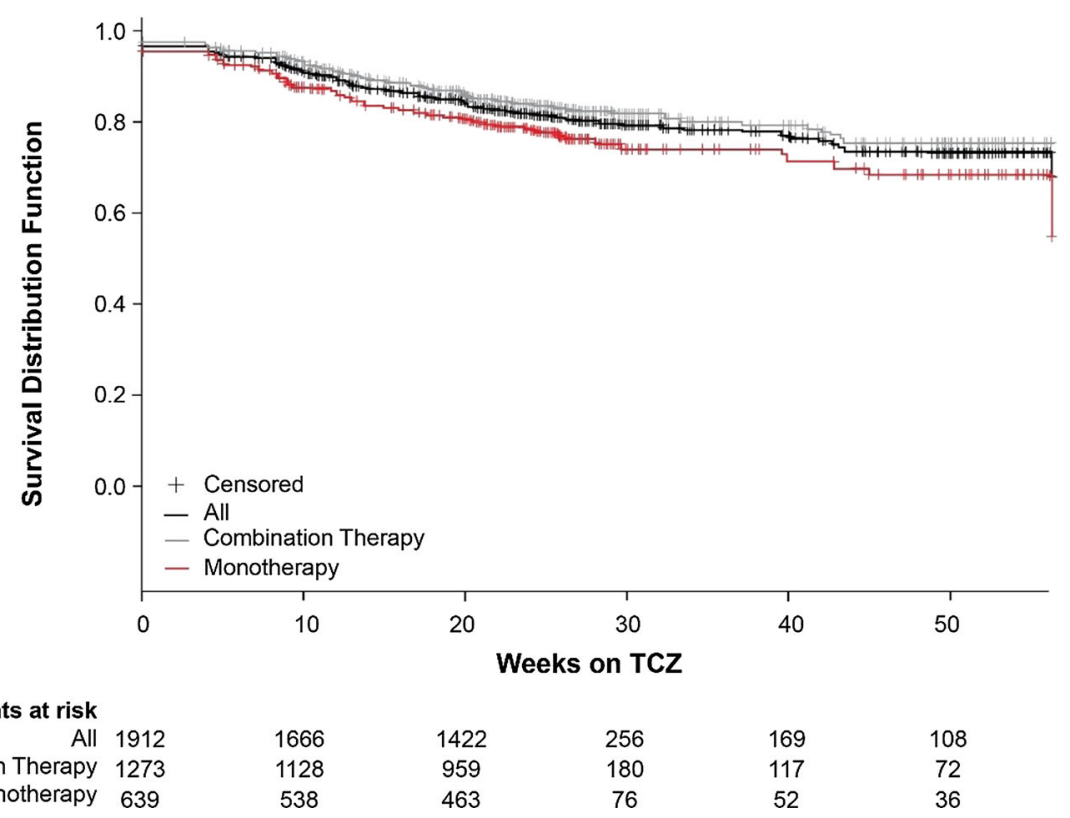

Fig. 2 Kaplan-Meier curves of duration on tocilizumab (TCZ; first to last dose) stratified by biologic exposure at baseline (a) and by TCZ treatment (b)

from baseline to month 6 was achieved by $68.9 \%$ of patients overall. The proportions of biologic-naive and biologic-exposed patients who had a meaningful reduction in HAQ-DI were $74.8 \%$ and $62.3 \%$, respectively.

\section{Safety}

Of the total study population, 817 patients (42.7\%) experienced $\geq 1 \mathrm{AE}$ [179 events per 100 patient-years (PY)] and 118 patients (6.2\%) experienced an SAE (17 events per $100 \mathrm{PY}$ ). The most common AEs (affecting $\geq 5 \%$ of patients) 
Table 2 Concomitant medication use

\begin{tabular}{|c|c|c|c|}
\hline \multirow[t]{2}{*}{ Treatment } & \multicolumn{2}{|c|}{$\begin{array}{l}\text { Baseline biologic } \\
\text { experience }\end{array}$} & \multirow{2}{*}{$\begin{array}{l}\text { All } \\
\text { patients } \\
n=1912\end{array}$} \\
\hline & $\begin{array}{l}\text { Biologic } \\
\text { naive } \\
n=1073\end{array}$ & $\begin{array}{l}\text { Biologic } \\
\text { exposed } \\
n=839\end{array}$ & \\
\hline $\begin{array}{l}\text { DMARDs, } \\
n(\%)\end{array}$ & $812(75.7)$ & $541(64.5)$ & $1353(70.8)$ \\
\hline \multicolumn{4}{|l|}{ Methotrexate } \\
\hline Baseline, $n(\%)$ & $553(51.5)$ & $361(43.0)$ & $914(47.8)$ \\
\hline $\begin{array}{l}\text { Dose at baseline, } \\
\text { mean (SD), g }\end{array}$ & $13.6(4.7)$ & $15.6(5.4)$ & $14.4(5.1)$ \\
\hline Month 6, $n(\%)$ & $375(34.9)$ & $272(32.4)$ & $647(33.8)$ \\
\hline $\begin{array}{l}\text { Dose at month } 6 \text {, } \\
\text { mean (SD), g }\end{array}$ & $13.8(4.9)$ & $15.3(5.3)$ & $14.5(5.1)$ \\
\hline \multicolumn{4}{|l|}{ Corticosteroids } \\
\hline Baseline, $n(\%)$ & $410(38.2)$ & $386(46.0)$ & $796(41.6)$ \\
\hline $\begin{array}{l}\text { Dose at baseline, } \\
\text { mean }(S D), \mathrm{g}^{\mathrm{a}}\end{array}$ & $8.8(5.6)$ & $8.1(5.1)$ & $8.5(5.4)$ \\
\hline Month 6, $n$ (\%) & $309(28.8)$ & $306(36.5)$ & $615(32.2)$ \\
\hline $\begin{array}{l}\text { Dose at month } 6 \text {, } \\
\text { mean }(\mathrm{SD}), \mathrm{g}^{\mathrm{a}}\end{array}$ & $7.6(4.6)$ & $7.7(5.2)$ & $7.7(4.9)$ \\
\hline
\end{tabular}

$D M A R D$ disease-modifying antirheumatic drug

a Prednisone equivalent

were from the following system organ classes: infections and infestations (13.9\% of patients), abnormal laboratory findings (investigations) (11.3\%), musculoskeletal and connective tissue disorders (6.3\%), gastrointestinal disorders $(5.9 \%)$, skin and subcutaneous tissue disorders (5.6\%), and blood and lymphatic system disorders (5.5\%) (Table 3). A total of 382 patients (20.0\%) experienced AEs that were determined by the investigator to be related to treatment (58 per $100 \mathrm{PY}$ ). AEs resulted in withdrawal from the study in 104 patients (5.4\%). The most common SAEs (affecting $\geq 1 \%$ of patients) were from the system organ class infections and infestations, reported in 35 patients $(1.8 \%)$. Eight deaths occurred during the study, with the causes reported to be one each of pneumonia, sepsis, pulmonary edema, respiratory failure, arrhythmia, malignant lung neoplasm, cerebrovascular accident, and shock; the report of respiratory failure was suspected by the investigator to be related to TCZ treatment. AEs and SAEs were reported in $34.2 \%$ and $4.9 \%$ of biologic-naive patients and in $53.6 \%$ and $7.7 \%$ of biologic-exposed patients, respectively. AEs and SAEs were reported in $47.1 \%$ and $7.4 \%$ of patients in the TCZ monotherapy group and in $40.5 \%$ and $5.6 \%$ of patients in the combination therapy group, respectively.

\section{DISCUSSION}

This multi-national, observational study evaluated the efficacy, safety, and patterns of usage with TCZ over a 6-month period in patients with RA. This analysis extends prior findings from an interim report [19] to provide a complete data set with a total of 1912 patients and describes PROs and other clinical outcomes among patients who were biologic naive vs. biologic experienced at baseline.

Analysis of treatment patterns in routine clinical practice showed that $51.6 \%$ of patients initiated TCZ as their first biologic and, overall, most patients $(81.2 \%)$ remained on TCZ at month 6. Retention rates were similar for patients who were biologic naive vs. biologic exposed and are consistent with previous realworld reports $[19,21-23]$ and with that observed in our interim results (82.9\%) [19]. A decrease in the use of concomitant csDMARDs was observed; although the overall mean (SD) dose of MTX among all patients receiving MTX was similar from baseline to month 6 [14.4 (5.1) mg per week to 14.5 (5.1) mg per week], the proportion of patients receiving concomitant MTX decreased from $47.8 \%$ at baseline to $43.0 \%$ at month 6 . In addition, patients with a change in MTX dose showed a reduction in weekly dose from baseline to month 6 [mean (SD) change, - 2.9 (5.5) mg]. This pattern of decreased concomitant csDMARD use may be an indirect measure of the effectiveness of TCZ. The observational FIRST Bio study of biologic-naive patients with RA initiating TCZ also reported a reduction in both the proportion of patients 


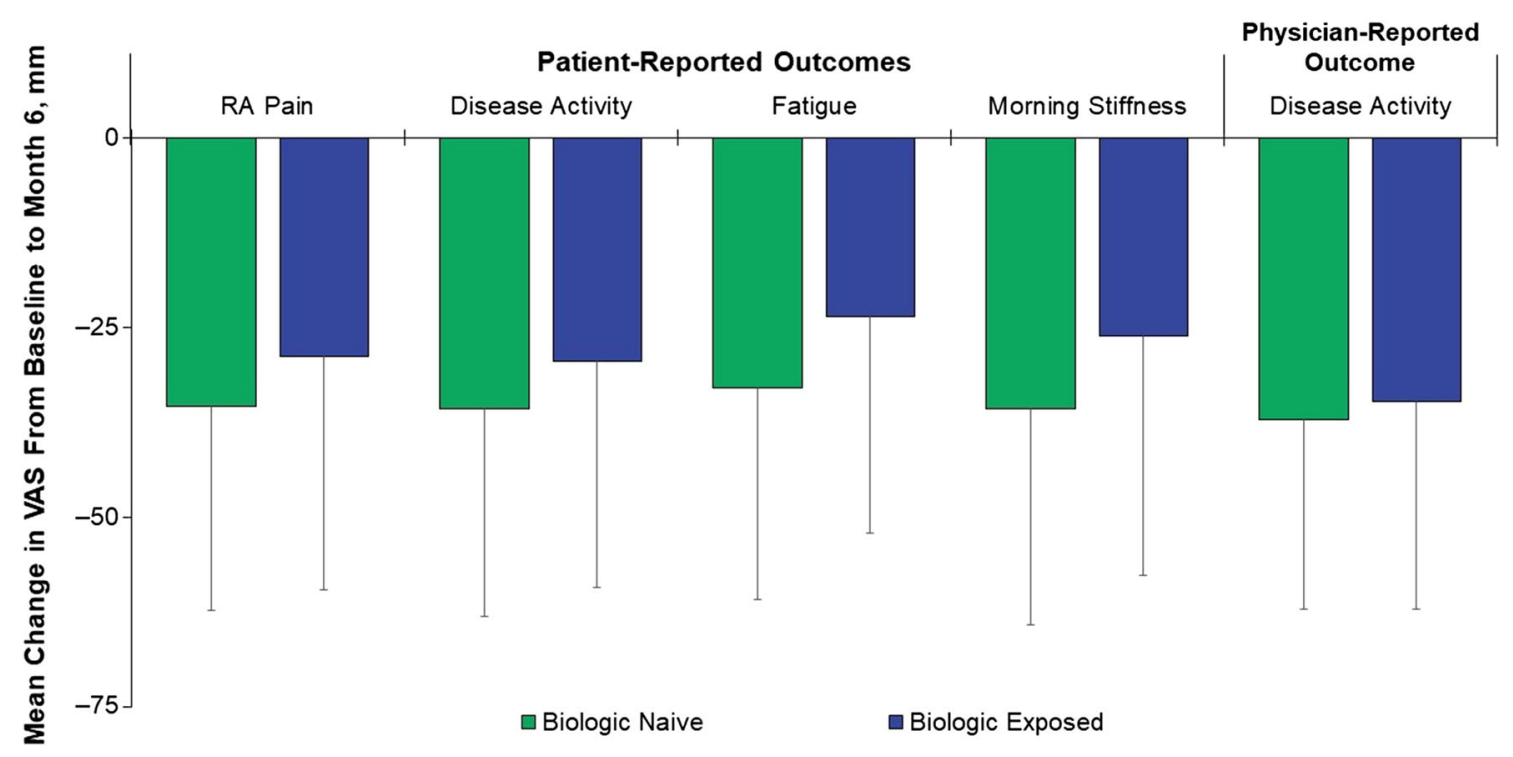

Fig. 3 Changes in quality-of-life outcomes from baseline to month 6. RA rheumatoid arthritis, VAS visual analog scale. Error bars denote standard deviation

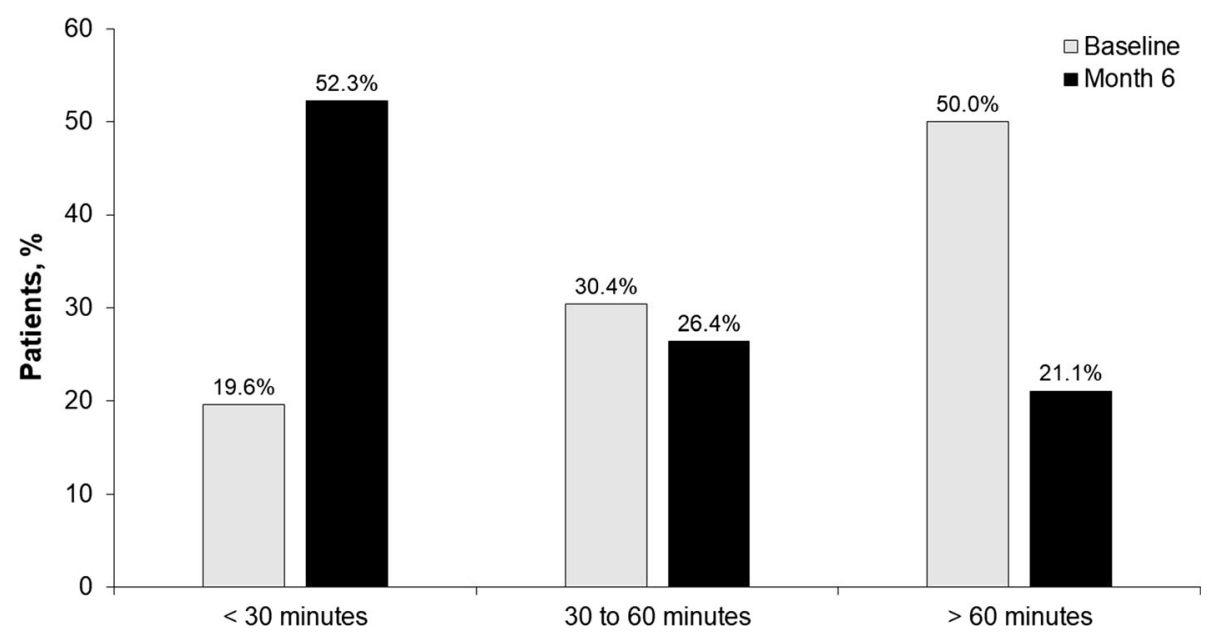

Fig. 4 Duration of morning stiffness at baseline and month 6

receiving concomitant MTX and the MTX dose at month 6 [9].

Given the AE profile and comorbidity risks of corticosteroids, current European League Against Rheumatism guidelines for the treatment of RA recommend that corticosteroids be tapered as rapidly as clinically feasible [24]. Thus, the use of corticosteroids is an important consideration when evaluating the efficacy of RA therapies. In our current analysis, a small decrease in mean (SD) daily dose of corticosteroids from baseline to month 6 was observed [8.5 (5.4)-7.7 (4.9) mg]. This finding is consistent with what we have reported previously using interim data from this study (TCZ monotherapy, 8.4-7.7 mg per day; TCZ combination therapy, 8.4-7.6 mg per day) [19]. In addition, patients in the present analysis with any change in corticosteroid dose had an overall reduction in daily dose from baseline to 
Table 3 Adverse events (AEs) by system organ class ${ }^{a}$

\begin{tabular}{|c|c|c|c|}
\hline \multirow{2}{*}{$\begin{array}{l}\text { Body system AE, } \\
n(\%) \text { of patients } \\
\text { with } \geq 1\end{array}$} & \multicolumn{2}{|c|}{$\begin{array}{l}\text { Baseline biologic } \\
\text { experience }\end{array}$} & \multirow{2}{*}{$\begin{array}{l}\text { All } \\
\text { patients } \\
n=1912\end{array}$} \\
\hline & $\begin{array}{l}\text { Biologic } \\
\text { naïve } \\
n=1073\end{array}$ & $\begin{array}{l}\text { Biologic } \\
\text { exposed } \\
n=839\end{array}$ & \\
\hline $\begin{array}{l}\text { Infections and } \\
\text { infestations }\end{array}$ & $90(8.4)$ & 175 & $265(13.9)$ \\
\hline Investigations & $118(11.0)$ & $98(11.7)$ & $216(11.3)$ \\
\hline $\begin{array}{l}\text { Musculoskeletal } \\
\text { and connective } \\
\text { tissue disorders }\end{array}$ & $44(4.1)$ & $77(9.2)$ & $121(6.3)$ \\
\hline $\begin{array}{l}\text { Gastrointestinal } \\
\text { disorders }\end{array}$ & $42(3.9)$ & $70(8.3)$ & $112(5.9)$ \\
\hline $\begin{array}{l}\text { Skin and } \\
\text { subcutaneous } \\
\text { tissue disorders }\end{array}$ & $41(3.8)$ & $66(7.9)$ & $107(5.6)$ \\
\hline $\begin{array}{l}\text { Blood and } \\
\text { lymphatic system } \\
\text { disorders }\end{array}$ & $54(5.0)$ & $51(6.1)$ & $105(5.5)$ \\
\hline All body systems & $367(34.2)$ & $450(53.6)$ & $817(42.7)$ \\
\hline
\end{tabular}

${ }^{\text {a }}$ Reported in $\geq 5 \%$ of all patients

month 6 [mean (SD) change, $-2.2(9.0) \mathrm{mg}$ ]. Corticosteroid-sparing effects of TCZ have similarly been observed in other real-world studies of TCZ use in routine practice conducted in Japan [9], France [25, 26], Australia [27], Germany [28], and the USA [29]. Together, these findings show that both TCZ monotherapy and combination therapy reduce the need for corticosteroids in patients with RA.

Mean DAS28 scores decreased from baseline to month 6 , with comparable improvements in patients receiving TCZ monotherapy and combination therapy. The overall rate of remission by DAS28 score at 6 months was $52.8 \%$ and is consistent with DAS28 remission rates reported after 6 months of treatment with TCZ in realworld studies [21, 30] and in clinical trials $[31,32]$. These findings suggest that the administration of DMARDs in combination with TCZ may not add additional clinical benefit over TCZ as monotherapy, which may reduce the exposure of patients to unnecessary added therapy. Similar rates of remission were also observed in patients who were biologic naive vs. biologic exposed, consistent with a recent study from the British Society of Rheumatology Biologics Register that found no significant difference in DAS28 remission between patients with RA initiating TCZ who were biologic naive and those who were biologic experienced [23]. In contrast, the realworld ACT-LIFE study found a significantly greater improvement in DAS28 at 6 months in patients treated with TCZ who were biologic naive vs. those who were biologic experienced [21]. Group differences in DAS28 response in the ACT-LIFE study may be explained in part by differences in disease severity at baseline between biologic-naive and biologic-experienced patients.

PROs are an integral component of understanding the impact of disease and treatment on symptoms, functioning, and other outcomes. In our current analysis, improvements were observed for all PROs, including patient assessment of pain and morning stiffness, patient and physician assessment of disease activity, and HAQ-DI score. Improvements in PROs are associated with an increased ability to participate in daily activities, including work and leisure pursuits, improved social and psychologic functioning, decreased pain, and an overall improvement in QOL [33]. Although no significant differences were found in the mean changes in scores between biologic-naive and biologic-exposed patients, biologic-naive patients had numerically greater improvement in all PROs, except for physician-reported outcome of disease activity, than patients who were biologic exposed. A real-world comparison of patients in the British Society of Rheumatology Biologics Register registry receiving TCZ as a first-line vs. subsequent-line biologic found that biologic-naive patients had a significantly greater improvement in HAQ score at 6 months and achieved the minimal clinically important difference in HAQ at a higher rate than in patients who were biologic exposed [23]. In contrast, an analysis of patients with RA in the US Corrona registry found numerically similar improvements with TCZ in most PROs between 
patients who were TNFi naive or TNFi exposed. In that study, $70.9 \%$ of TNFi-naive patients had previously received at least one non-TNFi biologic [34].

The safety profile of TCZ in this study was consistent with previous findings; no new AEs were reported $[35,36]$. The most common AEs and SAEs were infections and infestations, which was consistent with our interim findings [19] and with previous clinical trials of TCZ $[35,36]$. No difference in the frequency of AEs was observed between patients who received TCZ monotherapy and those who received combination therapy. A meta-analysis of TCZ clinical trials [37] and the French real-world ACT-SOLO study [38] similarly found no difference in the frequency of AEs in patients receiving TCZ monotherapy vs. combination therapy. Rates of AEs and SAEs were numerically more frequent in biologic-exposed patients than biologic-naive patients. This corresponds with what has been observed in a clinical trial of TCZ comparing AEs and SAEs in patients with a prior inadequate response to TNFi (TNFi-IR) with those in patients who were TNFi naive. Results from the trial showed a higher frequency of AEs and SAEs in patients with TNFi-IR than in those who were TNFi naive [32]. This difference in the frequency of events might be partly attributable to the longer disease duration or increased concomitant use of corticosteroids in patients with TNFi-IR, or to other factors, such as more frequent use of concomitant medications, that have been associated with TNFi-IR [39].

This study was not without limitations. Because this was a non-interventional study, TCZ dose, frequency, and duration were not dictated by the study protocol. This inevitably resulted in some variation between patients. The study population was restricted to patients receiving intravenous $\mathrm{TCZ}$, preventing conclusions about subcutaneous TCZ treatment. The largest proportion of patients were from China, where the duration of TCZ treatment was limited because of financial reasons. Finally, the comparison of biologic-naive vs. biologic-experienced subgroups was performed as a post hoc analysis, and comparisons between subgroups are restricted to descriptive terms.

\section{CONCLUSION}

This large, multi-national, non-interventional study indicates that both TCZ monotherapy and TCZ combination therapy are safe, effective, and well tolerated in patients with RA, with demonstrable improvement in patientand physician-reported outcomes. These improvements occurred irrespective of patients' biologic treatment history.

\section{ACKNOWLEDGEMENTS}

The authors thank the patients, investigators, and investigative staff at the clinical sites and the Roche Country Affiliate study teams who participated in this study.

Funding. Sponsorship for this study and article processing charges were funded by $F$. Hoffmann-La Roche.

Medical Writing Assistance. Support for third-party writing assistance, furnished by Amanda Borrow, PhD, of Health Interactions, Inc., was provided by F. Hoffmann-La Roche Ltd.

Authorship. All authors had full access to all of the data in this study and take complete responsibility for the integrity of the data and accuracy of the data analysis. All named authors meet the International Committee of Medical Journal Editors (ICMJE) criteria for authorship of this manuscript, take responsibility for the integrity of the work as a whole, and have given their approval for this version to be published.

Authorship Contributions. All authors are responsible for the content of this manuscript. The authors together conceptualized the manuscript content, interpreted the data, reviewed multiple drafts, and approved the final version for submission.

Disclosures. Boulos Haraoui is a consultant for AbbVie, Amgen, Eli Lilly, Merck, Pfizer, Sandoz, and UCB. Gustavo Casado has received 
personal honoraria and fees for consulting, lectures, and speaker bureaus from Pfizer, AbbVie, Roche, Janssen, Bristol-Myers Squibb, and Eli Lilly. László Czirják has received honoraria for consulting and lectures from Roche. Andrew Taylor has received speaker honoraria and travel/meeting attendance support from UCB, Bristol-Myers Squibb, Pfizer, AbbVie, Roche, and Eli Lilly and has received research funding from UCB. Peter Button is an employee of Roche. Yves Luder is an employee and shareholder of Roche. Roberto Caporali has received speaker and/or advisor fees from AbbVie, Bristol-Myers Squibb, Celgene, Eli Lilly, MSD, Pfizer, Roche, Sanofi-Genzyme, and UCB. Lingli Dong has nothing to disclose.

Compliance with Ethics Guidelines. All procedures performed in studies involving human participants were in accordance with the 1964 Helsinki Declaration and its later amendments or comparable ethical standards. Informed consent was obtained from all individual participants included in the study. As ACT-UP was an umbrella study, the study protocols, amendments, and informed consent documentation were approved by the respective local institutional review boards or independent ethics committees of the investigational centers.

Data Availability. The data sets generated during and/or analyzed during the current study are available to qualified researchers on reasonable request through the clinical study data request platform (www.clinicalstudydatarequest.com). Further details on Roche's criteria for eligible studies are available here (https://clinicalstudydatarequest.com/Study-Spon sors/Study-Sponsors-Roche.aspx). For further details on Roche's Global Policy on the Sharing of Clinical Information and how to request access to related clinical study documents, see here (https://www.roche.com/research_and_development/who_we_are_how_we_work/clinical_ trials/our_commitment_to_data_sharing.htm).

Open Access. This article is distributed under the terms of the Creative Commons Attribution-NonCommercial 4.0 International
License (http://creativecommons.org/licenses/ by-nc/4.0/), which permits any noncommercial use, distribution, and reproduction in any medium, provided you give appropriate credit to the original author(s) and the source, provide a link to the Creative Commons license, and indicate if changes were made.

\section{REFERENCES}

1. Harris ED Jr. Rheumatoid arthritis: pathophysiology and implications for therapy. $\mathrm{N}$ Engl J Med. 1990;322:1277-89.

2. Uhlig T, Moe RH, Kvien TK. The burden of disease in rheumatoid arthritis. Pharmacoeconomics. 2014;32:841-51.

3. Singh JA, Furst DE, Bharat A, et al. 2012 update of the 2008 American College of Rheumatology recommendations for the use of disease-modifying antirheumatic drugs and biologic agents in the treatment of rheumatoid arthritis. Arthritis Care Res (Hoboken). 2012;64:625-39.

4. Keystone EC, Kavanaugh AF, Sharp JT, et al. Radiographic, clinical, and functional outcomes of treatment with adalimumab (a human anti-tumor necrosis factor monoclonal antibody) in patients with active rheumatoid arthritis receiving concomitant methotrexate therapy: a randomized, placebo-controlled, 52-week trial. Arthritis Rheum. 2004;50:1400-11.

5. Klareskog L, van der Heijde D, de Jager JP, et al. Therapeutic effect of the combination of etanercept and methotrexate compared with each treatment alone in patients with rheumatoid arthritis: doubleblind randomised controlled trial. Lancet. 2004;363:675-81.

6. Maini R, St Clair EW, Breedveld F, et al. Infliximab (chimeric anti-tumour necrosis factor alpha monoclonal antibody) versus placebo in rheumatoid arthritis patients receiving concomitant methotrexate: a randomised phase III trial. ATTRACT Study Group. Lancet. 1999;354:1932-9.

7. RoActemra (tocilizumab $20 \mathrm{mg} / \mathrm{mL}$ concentrate for solution for infusion) [summary of product characteristics]. Welwyn Garden City, UK: Roche Registration Limited. 2015.

8. ACTEMRA (tocilizumab) [prescribing information]. South San Francisco, CA: Genentech, Inc. 2013. 
9. Ishiguro N, Atsumi T, Harigai M, et al. Effectiveness and safety of tocilizumab in achieving clinical and functional remission, and sustaining efficacy in biologics-naive patients with rheumatoid arthritis: the FIRST Bio study. Mod Rheumatol. 2017;27:217-26.

10. Strand V, Burmester GR, Ogale S, Devenport J, John A, Emery P. Improvements in health-related quality of life after treatment with tocilizumab in patients with rheumatoid arthritis refractory to tumour necrosis factor inhibitors: results from the 24-week randomized controlled RADIATE study. Rheumatol (Oxf). 2012;51:1860-9.

11. Fleischmann RM, Halland AM, Brzosko M, et al. Tocilizumab inhibits structural joint damage and improves physical function in patients with rheumatoid arthritis and inadequate responses to methotrexate: LITHE study 2-year results. J Rheumatol. 2013;40:113-26.

12. Emery P, Keystone E, Tony HP, et al. IL-6 receptor inhibition with tocilizumab improves treatment outcomes in patients with rheumatoid arthritis refractory to anti-tumour necrosis factor biologicals: results from a 24-week multicentre randomised placebo-controlled trial. Ann Rheum Dis. 2008;67:1516-23.

13. Burmester GR, Rigby WF, van Vollenhoven RF, et al. Tocilizumab in early progressive rheumatoid arthritis: FUNCTION, a randomised controlled trial. Ann Rheum Dis. 2016;75:1081-91.

14. Bijlsma JW, Welsing PM, Woodworth TG, et al. Early rheumatoid arthritis treated with tocilizumab, methotrexate, or their combination (U-Act-Early): a multicentre, randomised, double-blind, doubledummy, strategy trial. Lancet. 2016;388:343-55.

15. Jones G, Sebba A, Gu J, et al. Comparison of tocilizumab monotherapy versus methotrexate monotherapy in patients with moderate to severe rheumatoid arthritis: the AMBITION study. Ann Rheum Dis. 2010;69:88-96.

16. Dougados $M$, Kissel $K$, Sheeran $T$, et al. Adding tocilizumab or switching to tocilizumab monotherapy in methotrexate inadequate responders: 24-week symptomatic and structural results of a 2-year randomised controlled strategy trial in rheumatoid arthritis (ACT-RAY). Ann Rheum Dis. 2013;72:43-50.

17. Weinblatt ME, Kremer J, Cush J, et al. Tocilizumab as monotherapy or in combination with nonbiologic disease-modifying antirheumatic drugs: twentyfour-week results of an open-label, clinical practice study. Arthritis Care Res (Hoboken). 2013;65:362-71.
18. Choy E, Caporali R, Xavier R, et al. Subcutaneous tocilizumab in rheumatoid arthritis: findings from the common-framework phase 4 study programme TOZURA conducted in 22 countries. Rheumatol (Oxf). 2018;57:499-507.

19. Haraoui B, Casado G, Czirjak L, et al. Patterns of tocilizumab use, effectiveness and safety in patients with rheumatoid arthritis: core data results from a set of multinational observational studies. Clin Exp Rheumatol. 2017;35:899-906.

20. Arnett FC, Edworthy SM, Bloch DA, et al. The American Rheumatism Association 1987 revised criteria for the classification of rheumatoid arthritis. Arthritis Rheum. 1988;31:315-24.

21. Balsa A, Tovar Beltran JV, Caliz Caliz R, et al. Patterns of use and dosing of tocilizumab in the treatment of patients with rheumatoid arthritis in routine clinical practice: the ACT-LIFE study. Rheumatol Int. 2015;35:1525-34.

22. Leffers HC, Ostergaard M, Glintborg B, et al. Efficacy of abatacept and tocilizumab in patients with rheumatoid arthritis treated in clinical practice: results from the nationwide Danish DANBIO registry. Ann Rheum Dis. 2011;70:1216-22.

23. Kihara M, Davies R, Kearsley-Fleet L, et al. Use and effectiveness of tocilizumab among patients with rheumatoid arthritis: an observational study from the British Society for Rheumatology Biologics Register for rheumatoid arthritis. Clin Rheumatol. 2017;36:241-50.

24. Smolen JS, Landewe R, Bijlsma J, et al. EULAR recommendations for the management of rheumatoid arthritis with synthetic and biological diseasemodifying antirheumatic drugs: 2016 update. Ann Rheum Dis. 2017;76:960-77.

25. Fortunet C, Pers YM, Lambert J, et al. Tocilizumab induces corticosteroid sparing in rheumatoid arthritis patients in clinical practice. Rheumatol (Oxf). 2015;54:672-7.

26. Saraux A, Rouanet S, Flipo RM, et al. Glucocorticoid-sparing in patients suffering from rheumatoid arthritis and treated with tocilizumab: the SPARE-1 study. Clin Exp Rheumatol. 2016;34:303-10.

27. Jones G, Hall S, Bird P, et al. A retrospective review of the persistence on bDMARDs prescribed for the treatment of rheumatoid arthritis in the Australian population. Int J Rheum Dis. 2018;21:1581-90.

28. Baganz L, Richter A, Kekow J, et al. Long-term effectiveness of tocilizumab in patients with rheumatoid arthritis, stratified by number of previous treatment failures with biologic agents: 
results from the German RABBIT cohort. Rheumatol Int. 2018;38:579-87.

29. Pappas DA, Etzel CJ, Best J, et al. Patterns of prednisone use in US patients with rheumatoid arthritis initiating treatment with tocilizumab in routine clinical practice. Arthritis Rheumatol. 2017;69 (Suppl 10) [abstract 1423].

30. Iking-Konert C, von Hinüber U, Richter $C$, et al. ROUTINE-a prospective, multicentre, non-interventional, observational study to evaluate the safety and effectiveness of intravenous tocilizumab for the treatment of active rheumatoid arthritis in daily practice in Germany. Rheumatol (Oxf). 2016;55:624-35.

31. Burmester GR, Feist E, Kellner H, Braun J, IkingKonert C, Rubbert-Roth A. Effectiveness and safety of the interleukin 6-receptor antagonist tocilizumab after 4 and 24 weeks in patients with active rheumatoid arthritis: the first phase IIIb real-life study (TAMARA). Ann Rheum Dis. 2011;70:755-9.

32. Bykerk VP, Ostor AJ, Alvaro-Gracia J, et al. Tocilizumab in patients with active rheumatoid arthritis and inadequate responses to DMARDs and/or TNF inhibitors: a large, open-label study close to clinical practice. Ann Rheum Dis. 2012;71:1950-4.

33. Lubeck DP. Patient-reported outcomes and their role in the assessment of rheumatoid arthritis. Pharmacoeconomics. 2004;22:27-38.

34. Harrold LR, John A, Reed GW, et al. Impact of tocilizumab monotherapy on clinical and patient- reported quality-of-life outcomes in patients with rheumatoid arthritis. Rheumatol Ther. 2017;4: 405-17.

35. Schiff $\mathrm{MH}$, Kremer JM, Jahreis A, Vernon E, Isaacs JD, van Vollenhoven RF. Integrated safety in tocilizumab clinical trials. Arthritis Res Ther. 2011;13:R141.

36. Bykerk VP, Ostor AJ, Alvaro-Gracia J, et al. Comparison of tocilizumab as monotherapy or with add-on disease-modifying antirheumatic drugs in patients with rheumatoid arthritis and inadequate responses to previous treatments: an open-label study close to clinical practice. Clin Rheumatol. 2015;34:563-71.

37. Teitsma XM, Marijnissen AK, Bijlsma JW, Lafeber FP, Jacobs JW. Tocilizumab as monotherapy or combination therapy for treating active rheumatoid arthritis: a meta-analysis of efficacy and safety reported in randomized controlled trials. Arthritis Res Ther. 2016;18:211.

38. Flipo R, Maillefert J, Chazerain P, Idier I, Coudert M, Tebib J. Factors influencing the use of tocilizumab as monotherapy in patients with rheumatoid arthritis in a real-life setting: results at 1 year of the ACT-SOLO study. RMD Open. 2017;3:e000340.

39. Emery $P$, Dorner T. Optimising treatment in rheumatoid arthritis: a review of potential biological markers of response. Ann Rheum Dis. 2011;70:2063-70. 